\title{
sciendo
}

\section{Jump Performance During Official Matches in Elite Volleyball Players: A Pilot Study}

\author{
by \\ Ricardo Franco Lima ${ }^{1,4}$, José M. Palao², Filipe Manuel Clemente ${ }^{1,3}$
}

\begin{abstract}
The purpose of this pilot study was to assess the types and intensity of the jumps that professional male volleyball players executed. Seven male elite volleyball players participated in this study. The sample was composed of 1599 jumps performed in 15 sets of five official matches of the regular season of a professional team. A descriptive pilot study design was implemented to analyze the types of jumps and jump heights by particular playing positions (outside hitters, setter, and middle blockers). The jump height was recorded using an inertial measurement device. No significant differences in the heights of jumps were found between the sets of the matches. Different players' roles had different frequencies for different types of jumps and jump intensities. The data provide reference values of the type of jumps performed, their frequency, and intensity by particular playing positions in competition. The results confirm the need to individualize the practice and training of volleyball players according to the players' roles. Extensive studies are needed to provide more information about repeated jump ability in volleyball players.
\end{abstract}

Key words: team sport, performance, jumping, match analysis, monitoring.

\section{Introduction}

Volleyball is a non-invasive net sport. Teams perform alternative high-intensity actions of passing a ball and trying to send it to the opponent's court (Sheppard et al., 2007). The actions that involve jumps and are done near the net (e.g., spike and block) have a higher impact on performance (Voigt and Vetter, 2003). Player's anthropometry, technique, and vertical jump height are critical for the execution of such actions. For this reason, part of training of volleyball players focuses on the development of one's jumping ability (Freitas et al., 2014). Such training must consider game demands when it comes to establishing its volume, intensity, and type (Aoki et al., 2007; Bompa and Carrera, 2005; Kraemer et al., 2012; Mikolajec et al., 2012, 2017). Traditionally, monitoring players' jumping ability in a competition involves the assessment of the types and the number of jumps that the players perform.
Previous studies showed that players' game demands changed according to the players positions and their specificity (Esper, 2013; Sheppard et al., 2009). Less is known about the intensity of the players' jumps and how their jumping ability changes throughout the game. Do players execute all actions at high intensities? What jump intensities do the different game actions involve? How does the players' jumping ability change throughout the game? This lack of information can affect the criteria that guide the jump training program design.

Regarding jump frequency, at the international level, setters are responsible for organizing the attack of their teams. Setters perform around 18-22 jumps per set (Esper, 2013). In elite teams, setters use the jump set more because it allows them to accelerate their teams' offense and make a block by the opponent difficult

\footnotetext{
1 - Instituto Politécnico de Viana do Castelo, Escola Superior de Desporto e Lazer, Melgaço, Portugal.

2 - Department of Health, Exercise Science and Sport Management. University of Wisconsin-Parkside, Kenosha, WI, USA.

3 - Instituto de Telecomunicações, Delegação da Covilhã, Portugal.

4 - Research Center in Sports Sciences, Health Sciences and Human Development (CIDESD), Portugal.
} 
(Palao and Martinez, 2013). Outside hitters play on the outside, lateral portion of the court, participating in the reception and in the team offense. Outside hitters perform 12-18 jumps per set (Esper, 2013; Sheppard et al., 2009). Middle blockers play at the center of the net and perform quick attacks of the team. Middle blockers make around 18-23 jumps per set (Sheppard et al., 2009). They also have higher participation in blocks because this position allows them to block in all zones of the net. Less is known about jump intensity. A study with elite, male Polish players showed that players executed their jumps during the game at between $77-90 \%$ of their maximal potential and that the intensities of these jumps changed throughout the game (Wnorowski et al., 2013). However, another study with elite, female Argentinean players found, in assessments carried out after matches, that players' maximal jumping ability did not decrease after a match (Esper, 2003). These studies did not consider the type of jumps made during the game or their intensity. However, since the way of execution affects the jump height, this could result in incorrect data interpretation. The attack is performed with an approach and a strong arm swing. The block is executed with or without a lateral approach and with a short arm swing. The jump set is usually done without a run approach and without an arm swing.

Knowing how players execute the different types of jumps during a game can provide new insights into the quality of their specific strength training and can also help with the design of volleyball players' training. Current advances in technology allow players to wear small devices that do not interfere with their actions (Charlton et al., 2016). These devices can provide objective information about the intensities of the jumps that players perform (Charlton et al., 2013; Mahmoud et al., 2015) and help with assessing aspects of the game demands that we previously could not monitor, such as jump intensity. The miniaturization of monitoring devices allows volleyball coaches as well as strength and conditioning coaches to increase their knowledge about the game demands and to assess these aspects in each player. The purpose of this pilot study was to assess the types and intensities of the jumps that professional male volleyball players executed according to particular playing positions.

\section{Methods}

Participants

Seven male elite volleyball players of a team from Portugal's first division participated in this study. The characteristics of the players were as follows: age, $26.7 \pm 7.2$ years; body height, 1.93 $\mathrm{m} \pm 0.08 \mathrm{~m}$; body mass, $86.5 \pm 6.3 \mathrm{~kg}$; and experience in the first division, $5.14 \pm 5.35$ years). The playing positions of the analyzed players were three middle blockers, one setter, and three outside hitters. The sample was composed of 1496 jumps performed in 16 sets of five official regular-season matches (January and March, 2017, first phase of the first division of the Portuguese championship, total of 372 minutes of competition) in which 4 matches ended with a 3-0 and 1 match with a 3-1 final score. The sample included only data from sets of 25 points. The researchers contacted coaches and players, and they agreed to participate voluntarily in the study. Informed consent was obtained from all participants, including the coaches. All participants in the study were older than 18 years of age. An adaptation process for the research protocol was carried out before starting the data collection in practice (wearing monitoring devices). During the adaptation process (three practices in one week), one player decided not to withdraw from the study because he did not adapt to wearing the device (opposite player). The study followed the ethical recommendations of the Declaration of Helsinki for the study of humans.

Design and Procedures

A descriptive pilot study design was implemented to analyze the number and heights of jumps by sets (first, second, and third sets), types of jumps, and players' playing positions (middle blockers, setter, and outside hitters). Data related to the number and heights of jumps were collected using an inertial measurement unit, while data related to the types of jumps through the video analysis of the games. Eight types of jumps were differentiated: serve, reception, set, attack, simulation (fake attack by a spiker), block, celebration, and null (warm-up jump actions done between the rallies). A trained observer collected the data on jump types.

To determine the number of the jumps and their heights, each participant wore an inertial measurement unit device with three gyroscopes and three accelerometers (VERT Classic, Florida, United States). This device had been previously 
validated $(\mathrm{r}=0.83-0.97)$ by comparing it with a three-dimensional motion analysis (Charlton et al., 2013; Mahmoud et al., 2015). The device had a small size $(0.049 \mathrm{~m}$ in length, $0.007 \mathrm{~m}$ in width, and $0.021 \mathrm{~cm}$ in height) and was light $(0.022 \mathrm{~kg})$. The average standard error of the device for assessing the jump height was $0.04 \mathrm{~m}$ (Charlton et al., 2016). The participants each wore a belt with the device on the hip (Figure 1). Each inertial measurement unit was connected via Bluetooth to a tablet application. Data of the warm-up and actions between sets were not included in the analysis. The device transmitted data to the app in real time. After each match, all data were exported to a spreadsheet.

Games were recorded with a digital video camera located on a side grandstand and on a tripod. The observer had a degree in sport sciences, the highest national coach certification, and more than 10 years of experience in performance analysis in volleyball. Before starting the data collection, the observer completed specific training. The reliability of the data collection was established via a test-retest process $(10 \%$ of the data). The re-test was done after a 20-day interval to avoid task familiarity issues (Robinson and O'Donoghue, 2007). The intra-reliability value was 0.90 (Cohen's Kappa).

Data from the inertial measurement device and observation were integrated into one spreadsheet. Data from the video recording and the inertial measurement unit was synchronized using the moment of the beginning of the match. The unit of analysis was the jump. The number and moments of jumps quantified via the inertial measurement unit were the same as the number of jumps quantified via the observer. From the data recorded, the percentage of jump intensity was calculated using the maximal jump performed by each player for the different actions. The maximal effort of reference, in this study, was considered to be the one that players executed during the game, for each action, due to different characteristics and ways of execution for each action of the game (serve, reception, set, attack, and block). For the simulation, celebration and null jumps, the maximal effort of the attack was used. The jump intensity was expressed in the percentage of the maximal jump. The data are presented by total jump occurrence and by jumps that one player performed in a set ( 25 points). Jump frequency was standardized using the hour as the reference unit of time (X jumps per hour). All players involved in the study were starters in the match, and middle blockers were substituted by the libero in backcourt zones (zones 1, 6, and 5).

Statistical Analysis

A descriptive (mean, standard deviation, and percentages) and an inferential analysis were performed using SPSS statistical analysis software (SPSS version 23.0, Chicago, USA). A univariate MANOVA was used to test the differences among types of jumps with players' playing positions and match sets. A one-way ANOVA was used to test the variance of the heights of jumps per players' playing positions, sets, and types of action. The Tukey HSD Post Hoc test was used to analyze the influence of the different factors. The level of statistical significance was set at $p \leq 0.05$. The partial eta squared and the eta squared were used to calculate the effect sizes of the tests $\left(\eta_{-} \mathrm{p}^{\wedge} 2\right.$ and $\eta^{\wedge} 2$ ). Ferguson's classification for the $\eta^{\wedge} 2$ was used to analyze the effect sizes (Ferguson, 2009): no effect $(\mathrm{ES}<0.04)$; minimum effect $(0.04<\mathrm{ES}<0.25)$; moderate effect $(0.25<\mathrm{ES}<0.64)$; and strong effect (ES > 0.64).

\section{Results}

No significant differences in the analysis of the matches' different sets and types of action were found ( $p=0.472 ; \eta_{p}^{2}=0.009$ ). The difference in the jump height average between set was $0.01 \mathrm{~m}$. No significant differences in the heights of jumps between match sets were found $\left(p=0.681 ; \eta^{2}=\right.$ $0.001)$. Different types of actions had significantly different jump heights $\left(p=0.001 ; \eta^{2}=0.001\right)$. The attack actions involved significantly higher jump heights than the rest of the actions did. Simulation jumps, block jumps, and attack jumps involved significantly higher jump heights than did null jumps, serve jumps, set jumps, celebration jumps, and reception jumps $(p=0.001)$ (Table 1 and Figure 2).

Regarding the influence of players' playing positions, game sets, and types of action, the results showed significant relationships between playing positions and types of jumps $(p=$ $0.004)$. No effect size was found in the relationships among variables $\left(\eta_{p}^{2}=0.020\right)$. In addition, no significant interactions were found in the analysis of players' playing positions and match sets $(p=$ $\left.0.929 ; \eta_{p}^{2}=0.001\right)$, and in the analysis of players' 
playing positions, match sets, and types of action $\left(p=0.980 ; \eta_{p}^{2}=0.005\right)$. Significant differences in jump heights between players' playing positions were found with the one-way ANOVA ( $p=0.001$; $\left.\eta^{2}=0.102\right)$. Outside hitters had a significantly higher average jump height $(0.58 \mathrm{~m})$ than did middle blockers $(p=0.001)$ and the setter $(p=0.001)$. The setter had a significantly lower average jump height $(0.45 \mathrm{~m})$ than middle blockers $(p=0.001)$. From a descriptive analysis, middle blockers executed 50.2 jumps per hour, the setter performed 76.8 jumps per hour, and outside hitters executed 32.3 jumps per hour (Table 2).

Significant differences were found in the relative jump heights among types of jumps for middle blockers $\left(p=0.001 ; \eta^{2}=0.063\right)$, the setter $(p$ $\left.=0.001 ; \eta^{2}=0.372\right)$, and outside hitters $(p=0.048$; $\eta^{2}=0.032$ ). For middle blockers, significant differences in relative jump heights were found between block jumps and serve jumps $(p=0.003)$, attack jumps and serve jumps $(p=0.001)$, and simulated jumps and serve jumps $(p=0.001)$. The relative jump height of the serve jump was significantly lower than this of other jumps. Attack jumps and simulated attack jumps presented the lowest reductions in height.
Regarding the setter, significant differences in the relative jump heights were found between the following: null jumps and block jumps, attack jumps, serve jumps, celebration jumps, and reception jumps $(p=0.001)$; block jumps and set jumps $(p=0.001)$; set jumps and attack jumps $(p=0.001)$; serve jumps $(p=0.001)$; celebration jumps ( $p=0.043)$; and reception jumps $(p=0.003)$. In outside hitters, no significant differences were found among the relative jump heights of the different types of jumps.

Players of different playing positions presented significant differences in the relative jump heights for the different jump types. The setter and outside hitters had significantly higher values for relative jump heights than did middle blockers in the block $(p=0.001$ and $p=0.012$, respectively) and in the attack action ( $p=0.002$ and $p=0.001$, respectively). Middle blockers achieved a significantly smaller relative jump height in the serve action than did the setter $(p=0.001)$ and outside hitters $(p=0.001)$. The setter had significantly higher relative jump height values in the serve action compared to outside hitters $(p=0.001)$. No significant differences were found among playing positions in null jumps, simulation jumps, set jumps, celebration jumps, and reception jumps (Table 3 and Figure 3).

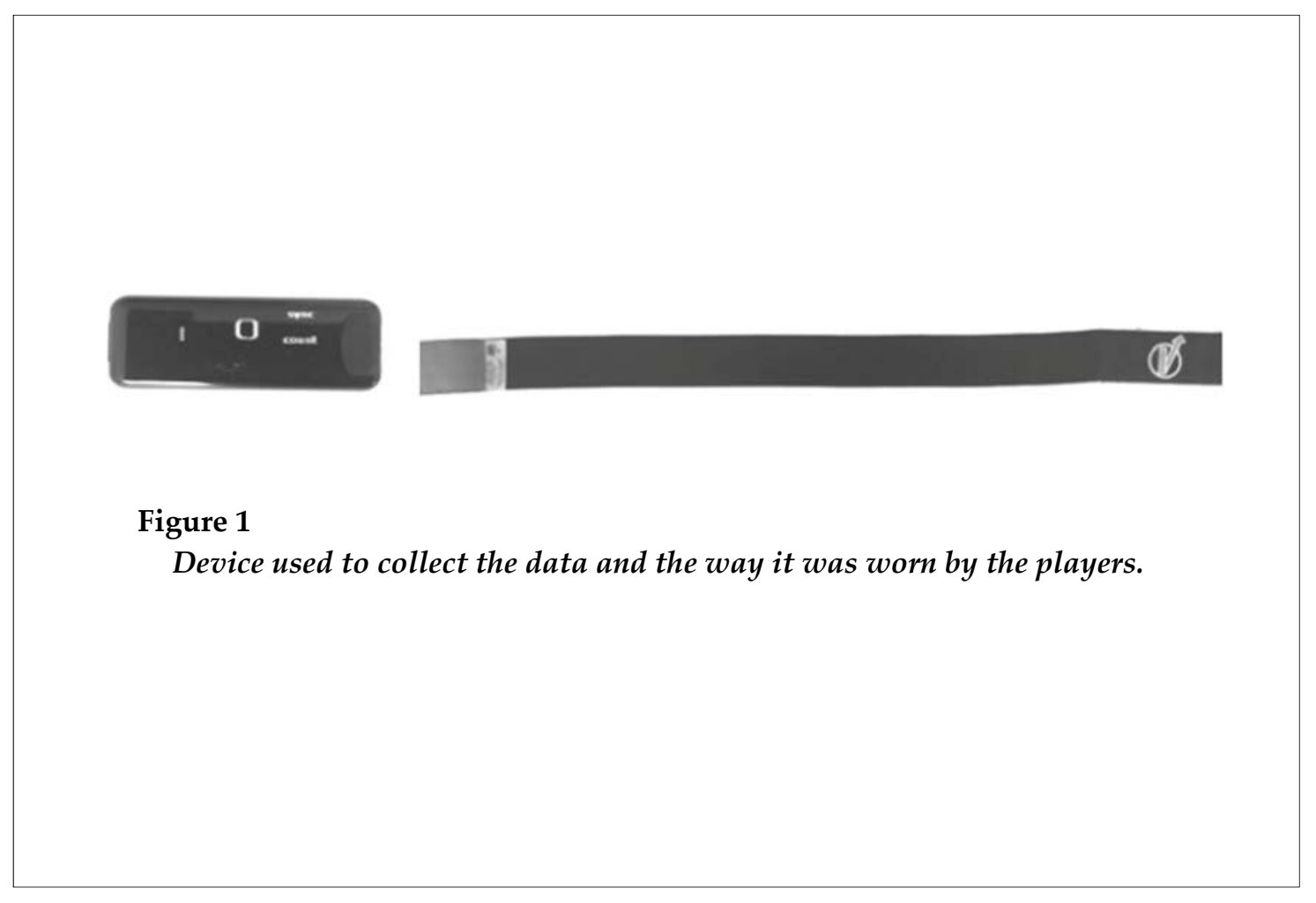


Table 1

Average and proportion of jumps per set and jump heights in different sets of the game (height values expressed in $m$ ).

\begin{tabular}{|c|c|c|c|c|c|c|c|c|c|c|c|c|}
\hline \multirow[b]{3}{*}{$\begin{array}{l}\text { Type } \\
\text { jump }\end{array}$} & \multicolumn{4}{|c|}{ First set } & \multicolumn{4}{|c|}{ Second set } & \multicolumn{4}{|c|}{ Third set } \\
\hline & \multicolumn{2}{|c|}{$\begin{array}{c}\text { Number of } \\
\text { jumps }\end{array}$} & \multicolumn{2}{|c|}{ Jump height } & \multicolumn{2}{|c|}{$\begin{array}{c}\text { Number of } \\
\text { jumps }\end{array}$} & \multicolumn{2}{|c|}{ Jump height } & \multicolumn{2}{|c|}{$\begin{array}{c}\text { Number of } \\
\text { jumps }\end{array}$} & \multicolumn{2}{|c|}{ Jump height } \\
\hline & Jccurrencr & $\%$ & M & SD & $\begin{array}{c}\text { Occurren } \\
\text { ce }\end{array}$ & $\%$ & M & SD & $\begin{array}{c}\text { Occurren } \\
\text { ce }\end{array}$ & $\%$ & M & SD \\
\hline Serve & 47 & 10.2 & 0.51 & 0.12 & 61 & 12.6 & 0.53 & 0.15 & 72 & 13 & 0.46 & 0.15 \\
\hline Reception & 9 & 1.95 & 0.35 & 0.13 & 7 & 1.45 & 0.32 & 0.11 & 8 & 1.45 & 0.28 & 0.08 \\
\hline Set & 100 & 21.7 & 0.39 & 0.11 & 85 & 17.6 & 0.41 & 0.11 & 104 & 18.8 & 0.39 & 0.11 \\
\hline Simulation & 19 & 4.12 & 0.64 & 0.13 & 26 & 5.38 & 0.56 & 0.16 & 32 & 5.8 & 0.59 & 0.11 \\
\hline Attack & 87 & 18.8 & 0.51 & 0.12 & 89 & 18.4 & 0.65 & 0.13 & 95 & 17.2 & 0.69 & 0.11 \\
\hline Block & 169 & 36.6 & 0.56 & 0.13 & 197 & 40.8 & 0.55 & 0.11 & 222 & 40.2 & 0.55 & 0.12 \\
\hline Celebration & 3 & 0.65 & 0.31 & 0.13 & 2 & 0.41 & 0.32 & 0.1 & 5 & 0.91 & 0.27 & 0.13 \\
\hline Null & 27 & 5.86 & 0.41 & 0.2 & 16 & 3.31 & 0.32 & 0.12 & 14 & 2.54 & 0.35 & 0.15 \\
\hline Total & 461 & 100 & 0.52 & 0.13 & 483 & 100 & 0.53 & 0.12 & 552 & 100 & 0.52 & 0.12 \\
\hline
\end{tabular}

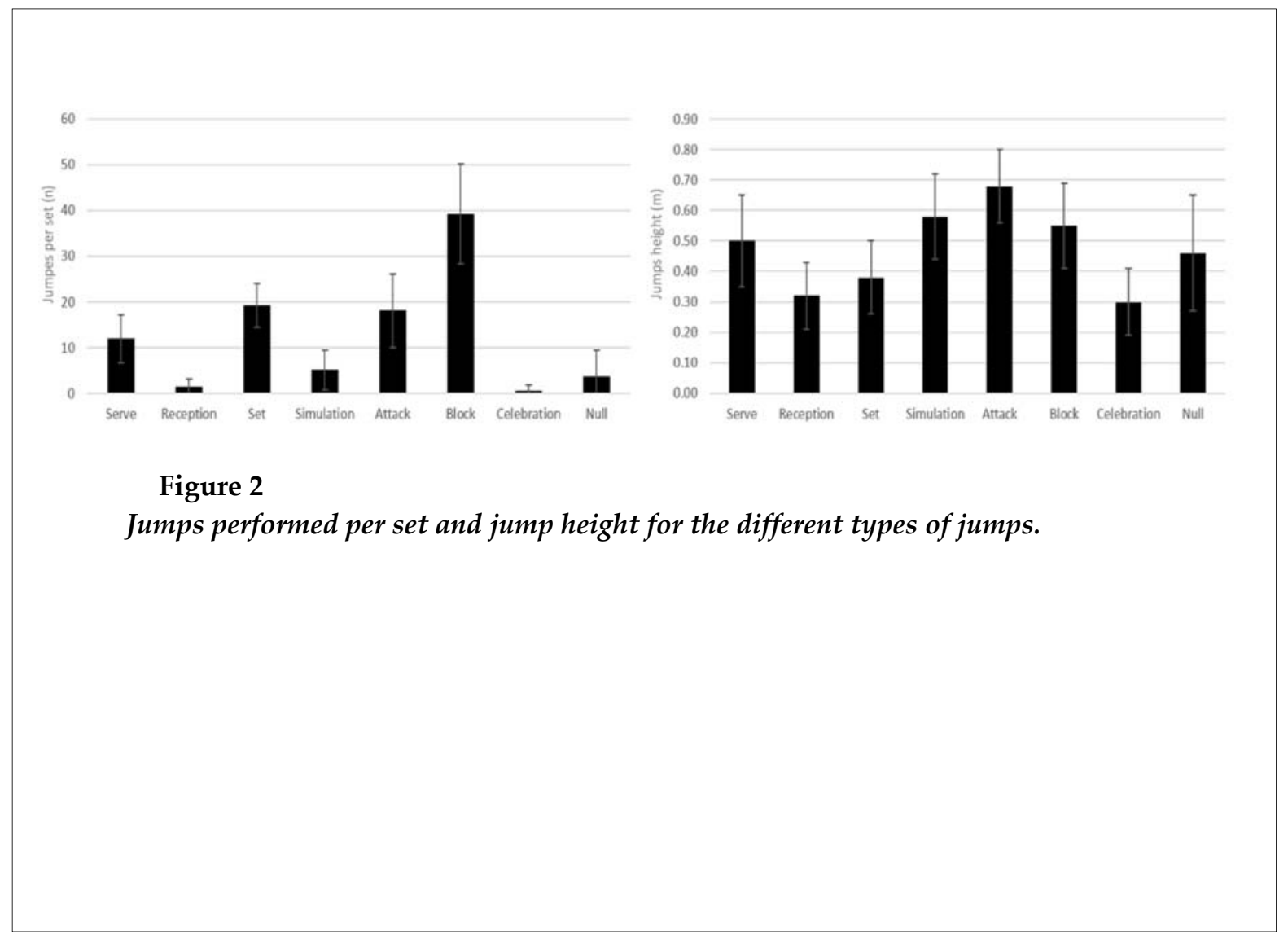


Table 2

Average and proportion of jumps per set and jump heights (height values expressed in $m$ ).

\begin{tabular}{|c|c|c|c|c|c|c|c|c|c|c|c|c|}
\hline \multirow[b]{3}{*}{$\begin{array}{l}\text { Type } \\
\text { jump }\end{array}$} & \multicolumn{4}{|c|}{ Middle blocker } & \multicolumn{4}{|c|}{ Setter } & \multicolumn{4}{|c|}{ Outside hitter } \\
\hline & \multicolumn{2}{|c|}{$\begin{array}{c}\text { Number of } \\
\text { jumps }\end{array}$} & \multicolumn{2}{|c|}{ Jump height } & \multicolumn{2}{|c|}{$\begin{array}{c}\text { Number of } \\
\text { jumps }\end{array}$} & \multicolumn{2}{|c|}{ Jump height } & \multicolumn{2}{|c|}{$\begin{array}{c}\text { Number of } \\
\text { jumps }\end{array}$} & \multicolumn{2}{|c|}{ Jump height } \\
\hline & Average & $\%$ & $\mathrm{M}$ & $\mathrm{SD}$ & $\begin{array}{c}\text { Averag } \\
\mathrm{e}\end{array}$ & $\%$ & $\mathrm{M}$ & SD & $\begin{array}{c}\text { Averag } \\
\mathrm{e}\end{array}$ & $\%$ & $\mathrm{M}$ & $\mathrm{SD}$ \\
\hline Serve & 1.6 & 7.89 & 0.41 & 0.14 & 3.9 & 12.2 & 0.54 & 0.1 & 4.9 & 18.3 & 0.52 & 0.16 \\
\hline Reception & 0.0 & 0.16 & 0.63 & 0 & 0.4 & 1.26 & 0.25 & 0.03 & 1.1 & 4.25 & 0.32 & 0.09 \\
\hline Set & 0.0 & 0.16 & 0.31 & 0 & 18.8 & 59.4 & 0.39 & 0.11 & 0.4 & 1.5 & 0.38 & 0.15 \\
\hline Simulation & 2.6 & 12.4 & 0.59 & 0.13 & 0.0 & 0 & 0 & 0 & 0.0 & 0 & 0 & 0 \\
\hline Attack & 4.3 & 20.6 & 0.65 & 0.12 & 0.6 & 1.9 & 0.55 & 0.07 & 8.9 & 33.5 & 0.68 & 0.12 \\
\hline Block & 11.0 & 53.3 & 0.53 & 0.12 & 6.8 & 21.4 & 0.58 & 0.1 & 10.3 & 38.7 & 0.58 & 0.12 \\
\hline Celebration & 0.0 & 0.16 & 0.22 & 0 & 0.4 & 1.26 & 0.39 & 0.08 & 0.2 & 0.75 & 0.17 & 0.02 \\
\hline Null & 1.1 & 5.31 & 0.37 & 0.16 & 0.8 & 2.53 & 0.35 & 0.2 & 0.8 & 3 & 0.39 & 0.18 \\
\hline Totals & 20.7 & 100 & 0.55 & 0.15 & 31.7 & 100 & 0.45 & 0.14 & $\begin{array}{l}13.3 \\
\end{array}$ & 100 & 0.58 & 0.12 \\
\hline
\end{tabular}

Table 3

Maximal and relative height per player's position for the different types of jumps (height values expressed in meters and percentages).

\begin{tabular}{|c|c|c|c|c|c|c|c|c|c|c|c|c|}
\hline & \multicolumn{4}{|c|}{ Middle blockers } & \multicolumn{4}{|c|}{ Setter } & \multicolumn{4}{|c|}{ Outside hitter } \\
\hline $\begin{array}{l}\text { Type } \\
\text { jump }\end{array}$ & $\begin{array}{l}\text { Highest } \\
(\mathrm{m})\end{array}$ & $\begin{array}{l}\text { Av. } \\
(\mathrm{m})\end{array}$ & $\begin{array}{l}\text { Av. } \\
(\%)\end{array}$ & $\begin{array}{l}\text { SD } \\
(\%)\end{array}$ & $\begin{array}{l}\text { Highest } \\
(\mathrm{m})\end{array}$ & $\begin{array}{l}\text { Av. } \\
(\mathrm{m})\end{array}$ & $\begin{array}{l}\text { Av. } \\
(\%)\end{array}$ & $\begin{array}{l}\text { SD } \\
(\%)\end{array}$ & $\begin{array}{l}\text { Highest } \\
(\mathrm{m})\end{array}$ & $\begin{array}{l}\text { Av. } \\
(\mathrm{m})\end{array}$ & $\begin{array}{l}\text { Av. } \\
(\%)\end{array}$ & $\begin{array}{l}\text { SD } \\
(\%)\end{array}$ \\
\hline Serve & 0.69 & 0.40 & 57.5 & 20.6 & 0.65 & 0.55 & 85.2 & 14.5 & 0.67 & 0.49 & 73.5 & 18 \\
\hline Reception & 0.63 & - & - & - & 0.30 & - & - & - & 0.39 & 0.29 & 74.8 & 19.5 \\
\hline Set & 0.49 & - & - & - & 0.69 & 0.39 & 57.2 & 16.2 & 0.48 & - & - & - \\
\hline Simulation & 0.80 & 0.57 & 71.2 & 16.3 & - & - & - & - & - & - & - & - \\
\hline Attack & 0.92 & 0.66 & 71.7 & 13.8 & 0.64 & - & - & - & 0.83 & 0.65 & 78.1 & 12.5 \\
\hline Block & 0.80 & 0.54 & 67 & 15.5 & 0.75 & 0.59 & 78.4 & 13.5 & 0.80 & 0.57 & 71.3 & 27.2 \\
\hline Celebration & 0.22 & - & - & - & 0.50 & - & - & - & 0.18 & - & - & - \\
\hline Null & 0.62 & 0.39 & 63.6 & 20.8 & 0.77 & - & - & - & 0.54 & - & - & - \\
\hline Average & 0.65 & 0.47 & 74.8 & 13.5 & 0.61 & 0.44 & 73.7 & 16.1 & 0.56 & 0.41 & 76.2 & 19.5 \\
\hline
\end{tabular}

Legend: Highest: Highest jumps recorded for a player in competition with the inertial measurement unit; Av.:

Average jump height; SD: Standard Deviation of the average jump height percentage.

Note: Data related to relative jump height were only included for actions occurring more than once per set 


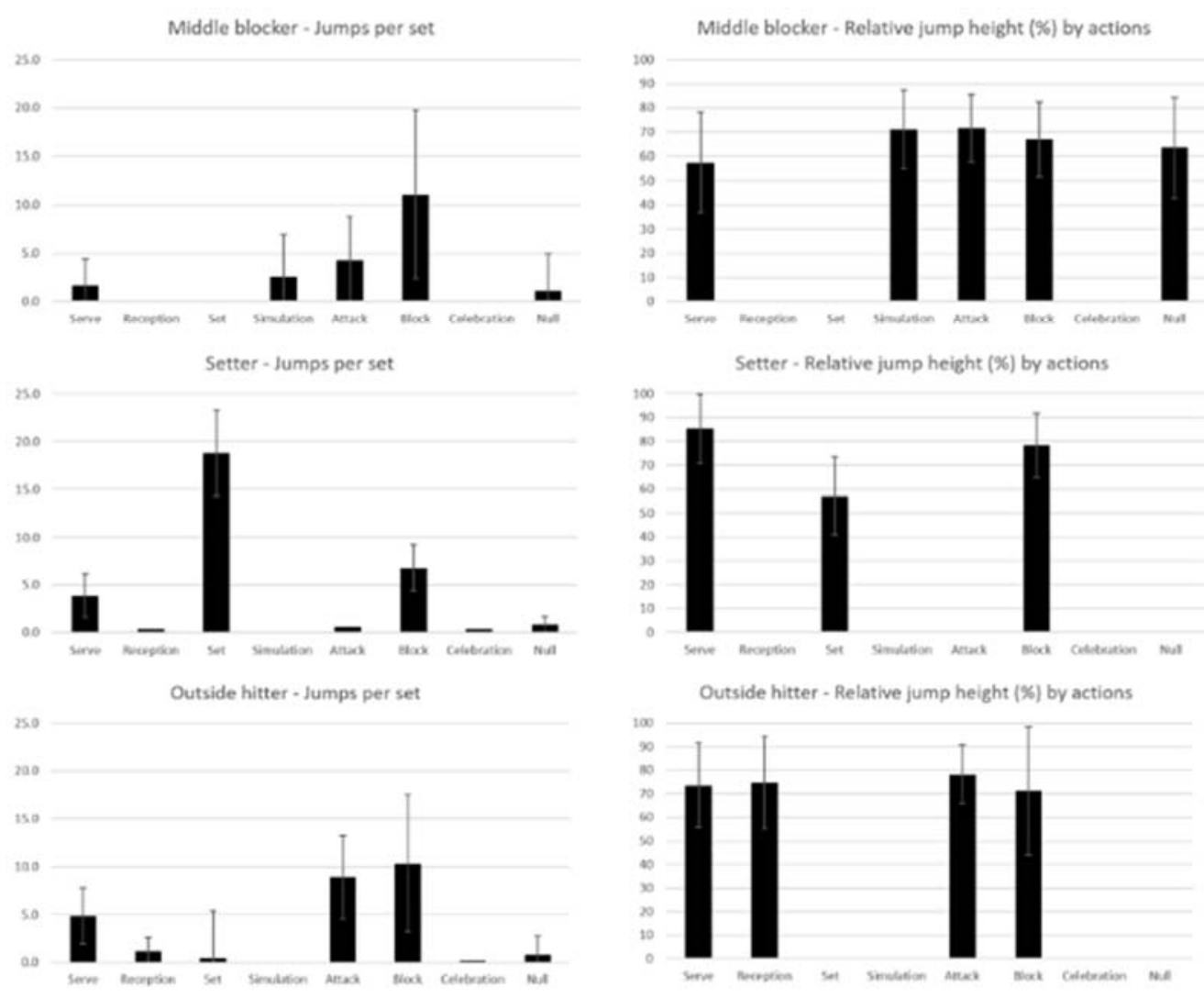

Figure 3

Jumps performed per set and relative jump heights for the different types of jumps (values expressed in numbers of jumps and percentages). Note: Data related to relative jump heights include only information for actions with more than one jump per set of occurrence.

\section{Discussion}

The aim of this pilot study was to assess the game demands regarding the number of jump actions and their intensities by particular playing positions. The data showed no changes in the types of jumps performed and in their intensities among the different game sets in the sample study. Thus, these results showed stable data between sets which is in opposition to results from a study by Wnorowski et al. (2013) with elite male Polish players (one match). They found a reduction of the relative jump heights throughout the match. It is possible that our players adapted their actions during the game to maintain their jumping ability, especially considering that previous studies showed that volleyball players maintained their jumping ability at the end of the game (Esper, 2003). Data of this study included only information from the games of three sets. More studies are needed to establish how players regulate the intensities of their jumps throughout the game.

Comparing the average jumps performed by sets, the data showed important differences in the game demands for the different players' roles. The setter executed 31.7 jumps on average (76.8 
jumps per hour), whereas middle blockers performed 20.7 jumps (50.2 jumps per hour) and outside hitters only 13.5 jumps (32.2 jumps per hour). When these values are extrapolated to a game of three, four, and five sets, the differences among different playing positions can be more than 54-80 jumps. These results emphasize the importance of individualizing jump training according to the players' position and the need to consider this aspect in the analysis of players' training loads. Our results are similar to those of previous studies for outside hitters and middle blockers, but they are higher for the setter. It is necessary to consider that the use of the jump set is related to the players' sports level. With higher performance levels of setters and teams comes a higher use of the jump set (Palao and Martinez, 2013). Setters use the jump set to try to increase the speed of the offense and their attack success. It is important to consider that each playing position should have its own reference values for assessing its load to individualize training.

The information related to the jump intensity (maximal and relative jump height) provides new evidence regarding how players adjust their actions throughout the game. The differences found in the maximal and relative jump heights among actions can be considered normal when the execution of each action and its goals are taken into consideration. For example, actions completed near the net present higher relative jump heights (attack and block) due to the importance of these actions in the game (Marcelino et al., 2010). Attack and simulated actions are carried out with a forward run-up approach, so it can be considered logical that spikes had higher jump heights than blocks. A higher contact height in the attack action involves a better incidence angle of the opponent court (Vint, 1998). However, the data showed that players did not execute their attack jumps at maximal capacity all of the time. The intensities of these actions varied from 55 to $90 \%$. The reason for this tendency could be that players adapted their efforts to the game situation and that they tried to maintain their performance throughout the game. In the analysis of the attack, it must be considered that players have greater reach when they attack than when they block due to the type of approach (frontal approach vs lateral or no approach) and how the ball is contacted (one hand vs. two hands at the same height). Other possible reasons behind the lower relative height jump values for block actions compared with attack actions are the players' need to collectively coordinate their temporal and spatial actions; a block is a rebound action and players put their hands over the net expecting to contact the ball in a situation with a time deficit (Selinger and Ackermann-Blont, 1986).

A set presented a lower relative jump height compared to an attack and a block. A set is not a terminal action. The goal of a set is to send the ball in the best possible condition to the spiker. Precision and hiding the pre-clues are critical in this action. A higher contact height involves an acceleration of the game, but setters must find a balance between precision and jump intensity. The results of this study showed that this balance was found between 51 and $73 \%$ of a setter's jump intensity. These results can be used as a reference to guide the jump load of practice for players to be prepared for the game's demands and reduce the risk of overuse injuries. If practice does not properly prepare athletes for competition, there is an increase in the risk of injury (Gabbett, 2016). What is defined as too much or not enough jumping or intensity depends on the different player positions. Previous studies showed that a high jump frequency in practice may contribute to the risk of a jumper's knee injury (Bahr and Bahr, 2014). However, the risk has to be individualized and it must consider the playing position.

Serves are done far from the net. However, higher ball contact allows to have a better angle of incidence on the opponent court (Huang and $\mathrm{Hu}$, 2007). Serve jumps are influenced by the type of a serve because they have different purposes and manners of execution. The goal of a power jump serve is to have higher height reach. A floating jump serve requires balance between precision in the contact and height reach. The use of different serve types among the players of this study is behind the variability in the relative jump heights of this action. The setter presented higher values for relative height jumps due to using the power jump serve (85\% of intensity), while middle blockers presented lower values for relative height jumps as they used the floating jump serve (57\%).

Analysis of the relative jump height for particular playing positions showed that middle blockers presented lower relative jump heights than the setter and outside hitters did in the serve, 
attack, and block actions. One possible explanation for these results is that middle blockers are taller, and have greater arm reach (Garcia-Alcaraz et al., 2014). Therefore, they can adjust their actions to the game situation to control their efforts better and to be able to maintain their jump ability throughout the rally and the match. The total relative jump height values for the different actions of the study sample are lower than the ones reported in previous research on elite, male Polish volleyball players (Wnorowski et al., 2013). These differences could be related to the levels of players, training performed, or the way height was measured (inertial sensor vs video analysis), among other possible factors. It must be considered that some of the differences found between outside hitters and middle blockers are close to the average standard error found with this measurement device $(0.03 \mathrm{~m})$. Future studies are needed to confirm these findings.

The current technology allows players to wear a small device that provides useful information about their actions (Charlton et al., 2016; Mahmoud et al., 2015). Currently, the use of such monitoring devices requires human participation to classify what types of actions are executed to interpret properly the game demands regarding jumping. The current devices cannot differentiate between actions. For example, actions with different purposes are combined, and outlier data are included in the analysis (e.g., celebration jumps or null jumps). Ideally, in the future, the information from these devices can be integrated with other systems of data collection used in sports, such as the statistical analysis of the players' actions. These will allow for categorizing properly the jumps that players perform. Technology provides new information, but human experts are necessary to classify, analyze, and interpret the data properly in order to benefit from it. This new information must be integrated with our current knowledge about the game demands (different types of jumps, different manners of execution, and different final outcomes of the actions). These results indicate the need to integrate strength and power training of a jump with the court practice of the athlete (e.g., adapt actions to the game situation).

This study presented useful information for volleyball coaches, strength and conditioning coaches, and sport performance researchers regarding the study of game demands and how players adjust their efforts during the game. The information related to jump intensity showed how players realized their jumps in competition. This paper introduced protocols and reference values for monitoring players' repeated jump ability (RJA). The data from the current study, due to the sample size, provide insight only into the RJA of elite male volleyball players and cannot be generalized. The lack of reference values involves the risk that volleyball and strength coaches may use the maximal test as the reference for jump training. Yet, it shall be kept in mind that players execute several types of jumps in competition; a maximal test of the vertical jump with a running approach should be a guide, but not the reference to guide training for all volleyball players. The results of this study showed the need to focus the assessment and training on players' ability to repeat and adapt their efforts throughout the game. Future studies are needed to provide RJA reference values for different levels, ages, and genders throughout the competitive season. The use of present-day technology allows to address new questions about monitoring and training methods, such as what training intensities or thresholds are more efficient at increasing or maintaining one's jumping ability, or at reducing the risk of overuse injuries in the lower limbs. In addition, this technology allows to be more specific in the analysis of game demands and their monitoring in practice as well as in competition, although the level of error for these devices must decrease in order to provide more precise information.

\section{Conclusion}

Players of different playing positions execute different types of jumps with varying frequency and at different intensities. No differences in the jumps executed in different game sets were found. The results showed that players adapted their jump actions to the game situations and that they maintained their RJA throughout the match. This paper provides reference values for monitoring jump training for middle blockers, setters, and outside hitters. Moreover, it provides reference values for the type of jumps performed, their frequency and intensity according to players' playing positions in competition. The results confirm the need to individualize volleyball 
players' training according to their playing positions. Yet, it should be kept in mind that the sports levels of the players could affect the number of jumps and their intensities throughout the game. The study provides new insight that suggests the need for rethinking the manner of monitoring game demands, training specificity, and jumping ability training in volleyball players. Additional studies are needed to provide more information about repeated jumping ability.

\section{References}

Aoki MS, Arruda AF, Freitas CG, Miloski B, Marcelino PR, Drago G, Drago M, Moreira A. Monitoring training loads, mood states, and jump performance over two periodized training mesocycles in elite young volleyball players. Int $J$ of Sports Sci Coach, 2017; 12(1): 130-7

Bahr MA, Bahr R. Jump frequency may contribute to risk of jumper's knee: a study of interindividual and sex differences in a total of 11.943 jumps video recorded during training and matches in young elite volleyball players. Br J Sport Med, 2014; 48: 1322-1326

Bompa T, Carrera M. Periodization training for sports. Champaign, IL: Human Kinetics; 2005

Charlton PC, Kenneally-Dabrowski C, Sheppard J, Spratford W. A simple method for quantifying jump loads in volleyball athletes. J Sci Med Sport, 2016; Available from: http://dx.doi.org/10.1016/j.jsams.2016.07.007

Esper A. Jumps performed by female players during a volleyball game. Rev Digit Educ Física y Deport, 2003; 8(58). Available from: http://www.efdeportes.com/efd58/saltos.htm

Esper A. Jumps performed by male volleyball players of a team of the Argentine League. Rev Digit Educ Física y Deport, 2013; 8(53)

Freitas VH, Nakamura FY, Miloski B, Samulski D, Mauricio G. Sensitivity of Physiological and Psychological Markers to Training Load Intensi- fication in Volleyball Players. J Sport Sci Med, 2014; 13(April): 571-9

Gabbett TJ. The training-injury prevention paradox: should athletes be training smarter and harder? Br J Sports Med, 2016; 50(5): 1-9. Available from: http://bjsm.bmj.com/content/early/2016/01/12/bjsports-2015095788.abstract

Garcia-Alcaraz A, Palao JM, Ortega E. Technical-tactical performance profile of reception according to competition category in men volleyball. Rev Kronos, 2014; 13(1): 1-9. Available from:

http://search.ebscohost.com/login.aspx?direct=true\&db=s3h\&AN=97447065\&lang=pt-br\&site=ehost-live

Huang C, Hu LH. Kinematic analysis of volleyball jump topspin and float serve. In: ISBS-Conference Proceedings Archive; 2007

Kraemer WJ, Comstock B, Clark JE, Dunn-Lewis C. Athlete needs analysis. In: Hoffman J, editor. NSCA's Guide to Program Design. Champain, IL: Human Kinetics, 10-26; 2012

Mahmoud I, Othman A, Abdelrasoul E, Stergiou P, Katz L. The reability of a real time wearable sensing device to measure vertical jump. Procedia Eng, 2015; 112: 467-72

Marcelino R, Mesquita I, Sampaio J, Moraes J. Study of performance indicators in male volleyball according to the set results. Rev Bras Educ Física e Esporte, 2010; 24(1): 69-78

Mikolajec K, Waskiewicz, Z, Maszczyk A, Bacik B, Kurek P, Zajac, A. Effects of stretching and strength exercises on speed and power abilities in male basketball players. Isokinet Exerc Sci, 2012; 20(1): 61-69

Mikołajec K, Maszczyk A, Chalimoniuk M, Langfort J. Gołaś A, Zajc A. The influence of strength exercises of the lower limbs on postural stability: A possible role of the autonomic nervous system. Isokinet Exerc Sci, 2017; 25(2): 79-89

Palao JM, Martínez S. Use of jump set regarding competition level in men's volleyball. SportTK, 2013; 2(1): 439 
Palao JM, Santos JA, Ureña A. Effect of team level on skill performance in volleyball. Int J Perform Anal Sport, 2004; 4(2): 50-60

Robinson G, O'Donoghue P. A weighted kappa statistic for reliability testing in performance analysis of sport. International. J Perform Anal Sport, 2007; 7(1): 12-9

Selinger A, Ackermann-Blount J. Arie Selinger's power volleyball. New York: St.Martin's Press; 1986

Sheppard JM, Gabbett T, Taylor K, Dorman J, Lebedew AJ, Borgeaud R. Development of a Repeated-Effort Test for Elite Men's Volleyball. Int J Sports Physiol Perform, 2007; 2: 292-304

Sheppard JM, Gabbett T. An Analysis of Playing Positions in Elite Men 's Volleyball: Considerations for Competition Demands and Physiologic Characteristics. J Strength Cond Res, 2009; 23(6): 1858-66

Vint PF. Hitting biomechanics: the foundation of skill application. Coach Volleyball, 10-5; 1998

Voigt $\mathrm{H}$, Vetter $\mathrm{K}$. The value of strength-diagnostic for the structure of jump training in volleyball. Eur J Sport Sci, 2003; 3(3): 1-10

Wnorowski K, Aschenbrenner P, Skrobecki J, Stech M. An assessment of a volleyball player's loads in a match on the basis of the number and height of jumps measured in real-time conditions. Balt J Heal Phys Act, 2013; 5(3): 199-206. Available from: http://ezproxy.library.yorku.ca/login?url=http://search.ebscohost.com/login.aspx?direct=true\&db=sph \&AN=91555970\&site $=$ ehost-live

\section{Corresponding author:}

\section{Ricardo Franco Lima}

Escola Superior de Desporto e Lazer,

Complexo Desportivo e de Lazer Comendador Rui Solheiro,

Monte de Prado, 4960-320 Melgaço, Portugal;

Phone number:00351965261337.

E-mail: ricardo.lima@esdl.ipvc.pt 